\title{
Relationship between economy and sustainability for a multi-storey reinforced concrete frame structure
}

\author{
A. Puskas ${ }^{1} \&$ L. M. Moga ${ }^{2}$ \\ ${ }^{I}$ Department of Structures, Technical University of Cluj-Napoca, \\ Romania \\ ${ }^{2}$ Department of Buildings and Management, \\ Technical University of Cluj-Napoca, Romania
}

\begin{abstract}
Reinforced concrete structures are not generally known as sustainable ones due to the excessive use of limited limestone resources and due to the possible negative impact on the environment of using large quantities of energy for producing the rebar and the structural concrete. Unfortunately, understanding the shortcomings of these structures is not equivalent to finding alternative structural solutions with much lower environmental impact, which could respond to the same design theme. If a multi-storey, multi-bay reinforced concrete frame building is given, choice of proper concrete and reinforcing steel quality can lead to substantial savings, but how can the savings be related to the environmental impacts? In order to study the relationship between the economy and the environmental impact for the same given frame structure the structural design has been carried out for two versions of material use, where the first version is based on concrete class $\mathrm{C} 16 / 20$ and reinforcing steel class PC52 while the second version uses concrete class $\mathrm{C} 30 / 37$ and reinforcing steel class S500. The next step is the comparison of the structural solutions by means of the material lists and the realization costs of the structures, but the final conclusions could not be deducted without taking into account the estimated required energy for realizing both structures. Based on the calculated structure the paper concludes by providing the relationship between the economy and the sustainability of the used structural materials.
\end{abstract}

Keywords: sustainability of concrete structures, economy and sustainability, material quality impact, cost and energy. 


\section{Introduction}

Structural designers are familiar with the essential requirements stated in the Council Directive 89/108/EEC [1] with respect to the mechanical resistance and stability, safety in case of fire, hygiene, health and environment, safety in use, protection against noise and energy economy and heat retention. In the formulation of the Eurocodes most of the requirements have been overtaken and implemented, especially the essential requirements for safety, serviceability and durability of structures [2], but without having any recommendation for energy economy or environment. For the realisation of commercial, residential and industrial buildings, structural concrete is the building material used on the largest scale. As a building material, structural concrete can hardly be considered to be a sustainable material in the narrow sense of the word, but for many commercial and industrial applications its use cannot be avoided. Design principles based on the limit state concept used in conjunction with a partial factor method [2] provide sufficient guidelines for realising reliable concrete structures, but if one intends to design sustainable concrete structures supplementary guidelines shall be necessary.

\section{Reinforced concrete sustainability}

The most sustainable building is no building at all [3], but we still cannot avoid use of reinforced concrete for building realisation. Sustainability of reinforced concrete is determined by the sustainability of the components used.

\subsection{Concrete sustainability}

Concrete is the most used construction material in the world [4]. The concrete itself is obtained in concrete plants by mixing constituents: aggregates, sand, cement, water, and chemical and mineral admixtures. While some of the components can be obtained without high energy consumption, with low waste production, in cement production high quantities of energy are needed and a large quantity of greenhouse gas is released.

For structural concrete, replacement of up to $30 \%$ of the virgin aggregates with coarse recycled-concrete aggregates can save important quantities of energy, with only a slight reduction in the compressive strength of the concrete [5] and an important quantity of recycled material is re-used; in concrete mixing graywater and rainwater can be used, which can reduce the use of natural resources. Due to their valuable properties, use of mineral admixtures (fly ash, silica fume, slag) in concrete is equivalent to saving important cement quantities from the mix, but also to an energy and greenhouse gas emission saving while reusing industrial waste [4].

Cement is obtained by using large quantities of limestone, endangering the limited limestone resources [4]. In cement production the most energyconsuming stage is the heating of the limestone and shale mixture to high temperature (approximately $1450^{\circ} \mathrm{C}$ ), then inter-grinding the resulting clinker 
with calcium sulphates and with industrial process wastes, such as blast furnace slag, limestone, natural pozzolana and industrial pozzolanic materials, e.g. fly ash, silica fume and burnt shale. Dry process state-of-the-art technologies require 3.3-3.6 GJ of energy to produce a ton of clinker and then grind it into cement; wet processes require approximately 56 to $66 \%$ more energy $[6,7]$.

\subsection{Reinforcement sustainability}

Reinforcing steel bars used for concrete structures are made of unfinished tempered steel, produced in a hot rolled process with subsequent superficial hardening by heat treatment. In order to ensure a better mechanical bond to the concrete, the structural reinforcement can be ribbed, with the ribs being obtained by running of the hot rolled smooth bars through rollers, deforming the bars to a ribbed shape.

While concrete is generally used for its compressive strength, the steel reinforcement is used to overtake the tension appearing in the cross sections of concrete elements, having a tensile strength about 100 times higher than the concrete, but very similar thermal expansion coefficient. Inconveniencies appear due to its unprotected surface, which allows corrosion reactions even under ambient environmental conditions, and due to its low heat resistance. These inconveniences disappear when proper concrete cover is assured.

Reinforcing steel is a $100 \%$ recyclable material; it can be produced from $100 \%$ recycled scrap steel as feedstock. When a reinforced concrete structure arrives at the end of its life cycle, steel reinforcements separated from the concrete can be recycled and used again without quality loss, becoming prime material for reinforcing steel production. The embodied energy values and the necessary energy input per tonne of reinforcing steel are based on the energy used to melt and reform it, which, due to the high temperatures needed for melting, is comparable to the energy used for clinker realisation, but is still less than half of the energy used for the melting and lamination of the structural steel [8]. Reinforcement recycling can contribute to $20 \%$ of the carbon emission reduction requested by the EU (by 2020, with respect to the level of 1990).

\section{Designing a multi-storey reinforced concrete structure}

\subsection{Description of the structure and of the loads}

In order to make the cost and energy based comparison of the impact of different material qualities used for the same reinforced concrete frame structure a model having 4 longitudinal and 3 transversal openings on four levels has been used. In the longitudinal direction the openings used are $5.40 \mathrm{~m}, 5.70 \mathrm{~m}, 5.70 \mathrm{~m}$ and 5.40 $\mathrm{m}$, respectively, while in the transversal direction the openings used are $5.70 \mathrm{~m}$, $6.00 \mathrm{~m}$ and $5.70 \mathrm{~m}$, respectively; hence the structure in plan is symmetric. In the elevation the heights are $4.00 \mathrm{~m}$ for the first floor and $3.60 \mathrm{~m}$ for the upper levels, the columns being considered fixed at the base level (fig. 1). Loads taken into consideration besides the weight of the structure have been the dead load 
given by the finishing, with $1.5 \mathrm{kN} / \mathrm{m}^{2}$ on the intermediate floors and $2.5 \mathrm{kN} / \mathrm{m}^{2}$ on the upper floor, the snow load of $1.60 \mathrm{kN} / \mathrm{m}^{2}$ on the upper floor, and the live load of $2.50 \mathrm{kN} / \mathrm{m}^{2}$ on the intermediate floors, supplemented with $0.80 \mathrm{kN} / \mathrm{m}^{2}$ for internal partitioning walls. On the beams on the perimeter of the structure a uniform distributed load of $8.00 \mathrm{kN} / \mathrm{m}$ has been taken into account as dead weight for the walls. Wind loads have been considered for a wind basic velocity pressure of $0.50 \mathrm{kPa}$. Seismic loads on the structure have been generated for the region characterized by the upper limit of the period of the constant spectral acceleration branch $T_{\mathrm{c}}=0.7 \mathrm{sec}$ and the design ground accelerations $\mathrm{a}_{\mathrm{g}}=0.16 \mathrm{~g}$, and medium ductility class provisions being chosen to be fulfilled [9].

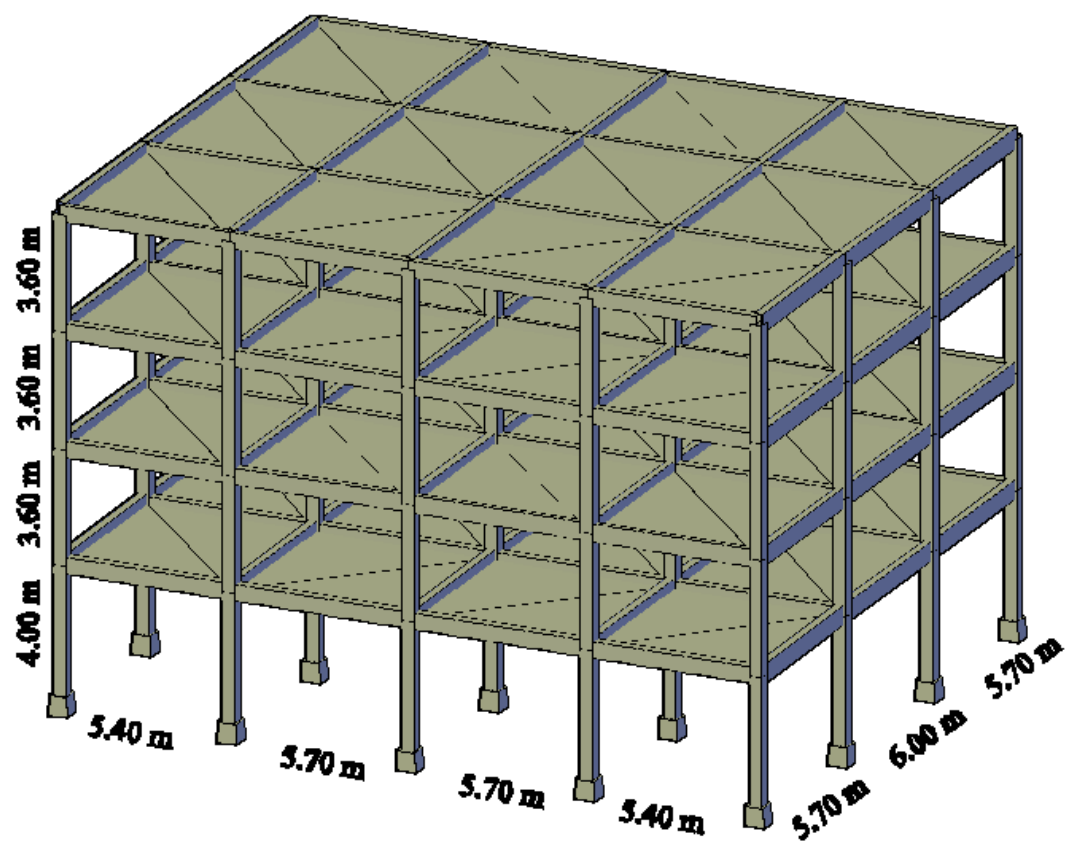

Figure 1: Typical layout of the structural elements.

\subsection{Structural design}

For the presented structure a first order linear-elastic analysis has been performed. In structural analysis, reduction of the elastic modulus has been considered: 0.5 for the seismic design situation, according to [10], and 0.8 and 0.6 for persistent and transient design situations established according to [2], for columns and beams, respectively, according to [11]. The structure has been analysed for two situations, corresponding to the concrete classes used: $\mathrm{C} 16 / 20$ for the first situation and $\mathrm{C} 30 / 37$ for the second situation. As a consequence, the dimensions of the structural elements have been established taking into consideration the limit deformations calculated in the serviceability limit states 
according to [2] and the limit deformations in both ultimate and serviceability limit states according to [10]. In this way, a $14 \mathrm{~cm}$ slab thickness for concrete class $\mathrm{C} 16 / 20$ and a $13 \mathrm{~cm}$ thickness for concrete class $\mathrm{C} 30 / 37$ have been established, where dimensions of the transversal beams of $30 \mathrm{~cm}$ by $60 \mathrm{~cm}$ and $25 \mathrm{~cm}$ by $60 \mathrm{~cm}$ respectively, dimensions of the longitudinal beams of $30 \mathrm{~cm}$ by $55 \mathrm{~cm}$ and $25 \mathrm{~cm}$ by $50 \mathrm{~cm}$ respectively, and dimensions of the columns of 45 $\mathrm{cm}$ by $45 \mathrm{~cm}$ and $40 \mathrm{~cm}$ by $40 \mathrm{~cm}$ respectively have been chosen. The reinforcements for the two situations have been imposed to be of quality PC52 and S500 respectively, resulting in a considerable difference in the quantities used for the two situations. The quantities for the two situations are presented in table 1 .

Table 1: $\quad$ Material quantities in the two situations.

\begin{tabular}{|l|r|r|}
\hline & C16/20, PC52 & C30/37, S500 \\
\hline Concrete $\left[\mathrm{m}^{3}\right]$ ]: & 216.32 & 200.87 \\
\hline - Slab & 62.64 & 52.20 \\
\hline - Transversal beams & 58.61 & 44.40 \\
\hline - Longitudinal beams & 59.94 & 47.36 \\
\hline - Columns & & \\
\hline Reinforcement[kg]: & $20,968.63$ & $18,854.07$ \\
\hline - Slab & $4,642.82$ & $2,553.76$ \\
\hline - Transversal beams & $4,614.87$ & $2,462.54$ \\
\hline - Longitudinal beams & $12,301.88$ & $10,139.40$ \\
\hline - Columns & &
\end{tabular}

\section{Cost impact of the material quality}

Based on the market prices for material and labour costs, the total prices of the structures have been calculated for the two situations studied: concrete class C16/20 and reinforcement quality PC 52 for the first situation and concrete class $\mathrm{C} 30 / 37$ and reinforcement quality S500 for the second situation. Table 2 presents the costs in case when C16/20 concrete quality and PC52 reinforcement are used, while table 3 presents the costs for $\mathrm{C} 30 / 37$ concrete quality and $\mathrm{S} 500$ reinforcement.

Table 2: $\quad$ Cost of the structure realisation for $\mathrm{C} 16 / 20$ and PC52.

\begin{tabular}{|l|r|r|r|}
\hline & Quantity & U.P. $[€]$ & \multicolumn{1}{c|}{ T.P. $[€]$} \\
\hline Concrete for slabs and beams $\left[\mathrm{m}^{3}\right]$ & 337.56 & 64.00 & $21,604.45$ \\
\hline Concrete for columns $\left[\mathrm{m}^{3}\right]$ & 121.25 & 64.24 & $7,789.08$ \\
\hline Rebars for slabs and beams $[\mathrm{kg}]$ & $30,226.32$ & 0.98 & $29,511.88$ \\
\hline Rebars for columns $[\mathrm{kg}]$ & $12,301.88$ & 0.98 & $12,011.11$ \\
\hline Formwork for slabs and beams $\left[\mathrm{m}^{2}\right]$ & $2,200.90$ & 12.00 & $26,410.75$ \\
\hline Formwork for columns $\left[\mathrm{m}^{2}\right]$ & 512.64 & 13.80 & $7,074.43$ \\
\hline
\end{tabular}


Table 3: $\quad$ Cost of the structure realisation for C30/37 and S500.

\begin{tabular}{|l|r|r|r|}
\hline & \multicolumn{1}{|c|}{ Quantity } & U.P. $[€]$ & \multicolumn{1}{c|}{ T.P. $[€]$} \\
\hline Concrete for slabs and beams $\left[\mathrm{m}^{3}\right]$ & 297.47 & 79.64 & $23,689.08$ \\
\hline Concrete for columns $\left[\mathrm{m}^{3}\right]$ & 96.60 & 79.88 & $7,716.06$ \\
\hline Rebars for slabs and beams $[\mathrm{kg}]$ & $23,870.37$ & 0.99 & $23,631.67$ \\
\hline Rebars for columns $[\mathrm{kg}]$ & $10,139.40$ & 0.99 & $10,038.01$ \\
\hline Formwork for slabs and beams $\left[\mathrm{m}^{2}\right]$ & $2,176.27$ & 12.00 & $26,115.26$ \\
\hline Formwork for Columns $\left[\mathrm{m}^{2}\right]$ & 456.96 & 13.80 & $6,306.05$ \\
\hline
\end{tabular}

It can be noted that the total cost of the structure in the first situation, when using C16/20 for concrete and PC52 for reinforcement, is 104,401.71 Euro, while in the second situation, when using C30/37 for concrete and S500 for reinforcement, it is $97,496.12$ Euro, i.e. with $6.6 \%$ reduction in price. The important price difference appears for the reinforcement, where the total price of the higher steel grade material is $18.9 \%$ cheaper than the total price of the lower steel grade material, the difference in the yield strengths of the used reinforcements being $29 \%$.

\section{Environmental impact of the material quality}

Comparison of the environmental impact for the used materials with different qualities is based on the comparison of the impact of the constituent materials. The main differences appear in the concrete mix proportioning. The quantities used for $1 \mathrm{~m}^{3}$ of concrete realisation and for the entire structure, for concrete classes $\mathrm{C} 16 / 20$ and $\mathrm{C} 30 / 37$, are presented in table 4 .

Table 4: $\quad$ Concrete mix proportions and total quantities.

\begin{tabular}{|l|r|r|r|r|}
\hline \multirow{2}{*}{ Constituent } & \multicolumn{2}{c|}{$\mathrm{C} 16 / 20$} & \multicolumn{2}{c|}{ C30/37 } \\
\cline { 2 - 5 } & $\begin{array}{c}\text { Unit } \\
\text { quantity } \\
{[\mathrm{kg} / \mathrm{m} 3]}\end{array}$ & $\begin{array}{c}\text { Total } \\
\text { quantity } \\
{[\mathrm{kg}]}\end{array}$ & $\begin{array}{c}\text { Unit } \\
\text { quantity } \\
{[\mathrm{kg} / \mathrm{m} 3]}\end{array}$ & $\begin{array}{c}\text { Total } \\
\text { quantity } \\
{[\mathrm{kg}]}\end{array}$ \\
\hline Cement & 360 & 165,173 & 480 & 189,151 \\
\hline Sand, 0-4 mm & 690 & 316,581 & 660 & 260,083 \\
\hline Fine aggregate, 4-8 mm & 510 & 233,995 & 390 & 153,686 \\
\hline Coarse aggregate, 8-16 mm & 670 & 307,405 & 630 & 248,261 \\
\hline Water & 180 & 82,586 & 225 & 88,665 \\
\hline Chemical admixture & 2.5 & 1,156 & 5 & 1,970 \\
\hline
\end{tabular}

If the energy consumption for producing cement is considered to be $3.38 \mathrm{GJ} / \mathrm{t}$ (medium value for year 2006) [6], the necessary energy for the cement quantity corresponding to the calculated building is $558.3 \mathrm{GJ}$ when using $\mathrm{C} 16 / 20$ concrete and 639.3 GJ when using $\mathrm{C} 30 / 37$ concrete. The necessary energy for the production of the concrete is presented in Table 5, where the necessary energy used for the concrete production has been considered as in [7]. The necessary 
energy for producing the whole concrete quantity is 620.4 GJ for the concrete class C16/20 and 688.7 GJ for the concrete class C30/37.

Table 5: Necessary energy for the concrete production.

\begin{tabular}{|l|r|r|r|r|}
\hline \multirow{2}{*}{ Constituent } & \multicolumn{2}{|c|}{$\mathrm{C} 16 / 20$} & \multicolumn{2}{c|}{ C30/37 } \\
\cline { 2 - 5 } & $\begin{array}{c}\text { For unit } \\
\text { quantity } \\
{\left[\mathrm{GJ} / \mathrm{m}^{3}\right]}\end{array}$ & $\begin{array}{c}\text { Total } \\
\text { quantity } \\
{[\mathrm{GJ}]}\end{array}$ & $\begin{array}{c}\text { For unit } \\
\text { quantity } \\
{\left[\mathrm{GJ} / \mathrm{m}^{3}\right]}\end{array}$ & $\begin{array}{c}\text { Total } \\
\text { quantity } \\
{[\mathrm{GJ}]}\end{array}$ \\
\hline Cement & 1.217 & 558.3 & 1.622 & 639.3 \\
\hline Sand, 0-4 mm & 0.062 & 28.5 & 0.059 & 23.4 \\
\hline Fine aggregate, 4-8 mm & 0.031 & 14.0 & 0.023 & 9.2 \\
\hline Coarse aggregate, $8-16 \mathrm{~mm}$ & 0.040 & 18.4 & 0.038 & 14.9 \\
\hline Water & - & - & - & - \\
\hline Chemical admixture & 0.002 & 1.1 & 0.005 & 1.9 \\
\hline
\end{tabular}

If the energy intensity value is taken to be $25.5 \mathrm{GJ} / \mathrm{t}$ according to [13] as a mean value for blast furnace-basic oxygen furnace production route, the necessary energy for the production of the whole reinforcement quantity when using reinforcing steel quality PC52 is $1084.5 \mathrm{GJ}$, while that in the case of using reinforcing steel quality S500 is 867.2 GJ.

From a consumed energy point of view, the total amount of energy for producing the necessary concrete and reinforcement for the structural solution using concrete class $\mathrm{C} 16 / 20$ and PC52 reinforcement is $1704.8 \mathrm{GJ}$, while the structural solution using concrete class $\mathrm{C} 30 / 37$ and S500 reinforcement is $1556.0 \mathrm{GJ}$.

\section{Discussion}

As stated earlier, sustainability of reinforced concrete is determined by the sustainability of the components used. The calculated structure is a simple but realistic one. The comparison of the structures has been limited to the economy of the structures and to the necessary energy used for producing the total amount of concrete and reinforcement for the two situations.

From an economic point of view, use of superior material quality for concrete leads to a price increase of $6.4 \%$, even if in the price calculation the steel quantity reduction has been considered. On the other hand, decrease of concrete quantity decreases the dead weight of the structure and allows for a decrease of reinforcement quantity when the minimum reinforcement ratio is imposing the necessary reinforcement. Use of superior quality ribbed reinforcement in conjunction with the reduction of the concrete quantity leads to a rebar price reduction of $18.9 \%$.

In the necessary energy calculation the costs in the construction phase, maintenance and demolition have not been considered, because the material manufacturing phase is the most energy consuming phase: during the site operations the energy used is much lower than in the material manufacturing phase, establishing the concrete mix and the concrete cover with respect to the 
environmental conditions and proper structural design can assure avoidance of all of the maintenance of the structure, and materials obtained from demolition of the reinforced concrete structure can be recovered and reused. In the manufacturing phase the necessary energy is $8.7 \%$ less in the case of using higher quality concrete and reinforcement.

\section{Conclusions}

Reinforced concrete structures when properly designed could be considered sustainable. The results obtained for both situations recommend use of superior quality material for both concrete and reinforcement, since use of higher quality materials leads to a global financial and energy economy. In the case of concrete the cost and energy used increase with the quality, but the quality increase allows a global cost reduction and energy saving for the structure. As a consequence, choice of proper concrete class needs a more detailed analysis than that presented. An engineering way of thinking should be developed in order to consider environmental criteria in the optimisation process besides the technical and financial aspects.

\section{References}

[1] Council Directive 89/108/EEC, http://eur-lex.europa.eu/

[2] Eurocode - Basis of structural design, EN 1990/1992

[3] Ecoshowcase, http://www.ecoshowcase.co.uk

[4] Naik T. R., Sustainability of Concrete Construction, CBU-2007-02, ASCE Practice Periodical on Structural Design and Construction, Vol. 13, No. 2, pp. 98-103, 2008

[5] Corinaldesi V., Structural concrete prepared with coarse recycled concrete aggregate: from investigation to design. Advances in Civil Engineering, Hindawi Publishing Corporation, 2011

[6] Cochez E., Nijs W., Simbolotti G., Tosato G., Cement Production. IEA ETSAP - Technology Brief I03 - June 2010: IEA ETSAP - Energy Technology Systems Analysis Programme

[7] Struble L., Godfrey J, How sustainable is concrete?, Proc. of the International Workshop on Sustainable Development and Concrete Technology, Ed. K. Wang, Iowa State University, pp. 201-212, 2004

[8] Sustainable Concrete, http://www.sustainableconcrete.org.uk

[9] Puskas A., Sandor G.A, Comparative Study of a Reinforced Concrete Structure for High and Medium Ductility, Treci International NauchoStrucni Skup GNP 2010, pp. 529-534, 2010

[10] P100-1/2006, Earthquake resistance design code - Part I - General design rules for buildings, 2006

[11] NP 007-97, Design code for reinforced concrete structures, 1997

[12] NE012-1:2007, Code of practice for execution of concrete, reinforced concrete and prestressed concrete works, Part I: Concrete production 2007

[13] Worldsteel, http://www.worldsteel.org 